\title{
OSTEOARTHRITIS OF THE TRAPEZIO-METACARPAL JOINT
}

\author{
Ch. Lasserre, D. Pauzat and R. Derennes, Bordeatx, France
}

The trapezio-metacarpal joint is the most important site for hypertrophic arthritis in the hand. The condition has been studied in France by Charcot and by Léri (1926), Robert (1936), Forestier (1937) and Huc and Badie (1941). We recently continued this work from both the radiological and clinical view, especially with regard to early diagnosis.

Anatomically, the trapezium is an intermediate bone placed in a particularly vulnerable position between the hammer of the first metacarpal and the anvil of the scaphoid. The normal arrangement of the bones is well known, but in about one case out of fifty the distal margin of the trapezium shows a marked exaggeration of the normal concavity (Fig. 3).

Physiologically, there are two main movements at the trapezio-metacarpal joint: antero-posterior flexion which is visible but difficult to analyse in radiographs, and lateral

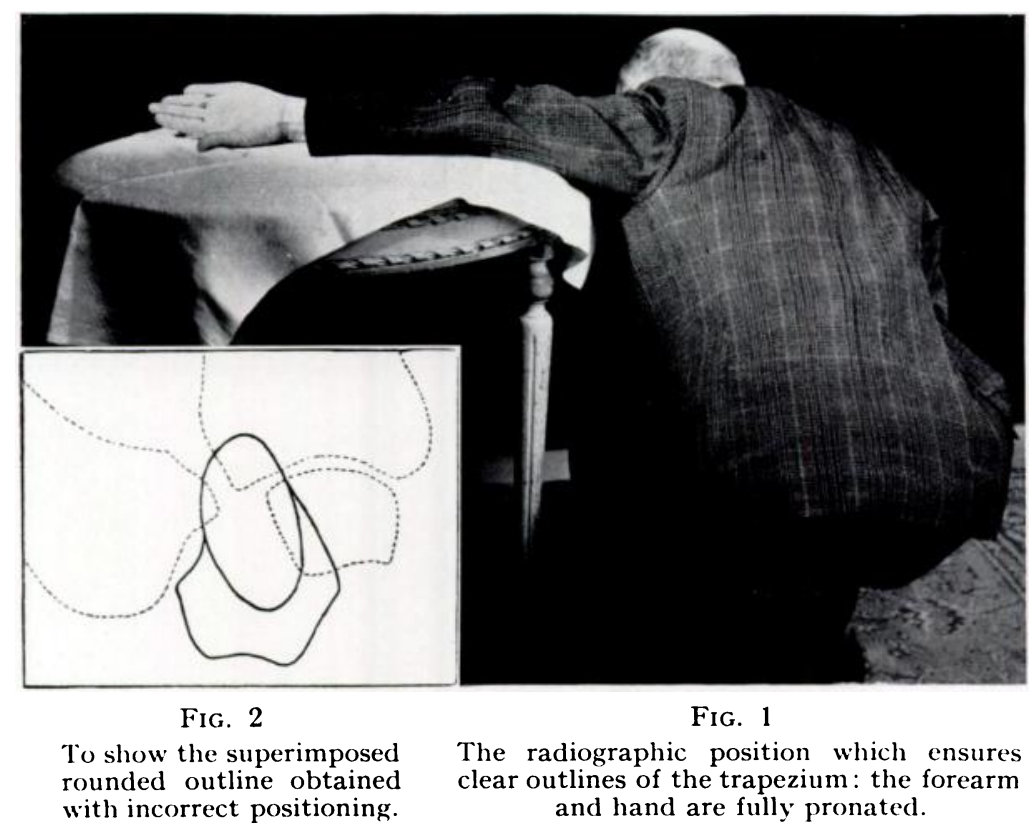

movement permitting abduction and adduction which is easy to study from radiographs made in forced pronation. These two movements are combined during opposition. Let us consider the lateral movement. During abduction the metacarpal fills exactly the transverse hollow of the trapezium (Fig. 4), but in adduction it slides laterally tending to leave the medial part (Fig. 5). The amount of sliding is usually very little, but in some cases the medial third of the hollow is uncovered. In rare instances the metacarpal is subluxated even during abduction, and this permanent physiological subluxation is a cause of error to be avoided (Fig. 6). The "step" sign of Forestier, le signe de la marche d'escalier, consists of a deformity of the base of the thumb caused by this radial subluxation of the first metacarpal.

Radiologically, the diagnosis of trapezio-metacarpal arthritis was difficult and uncertain until Robert (1936) demonstrated the value of placing the hand in forced pronation. The standard dorso-palmar film is of no practical use at all, except in advanced cases when it merely confirms the presence of a grave lesion of the joint. We must draw attention to possible errors in the interpretation of dorso-palmar views. At the level of the trapezium an 


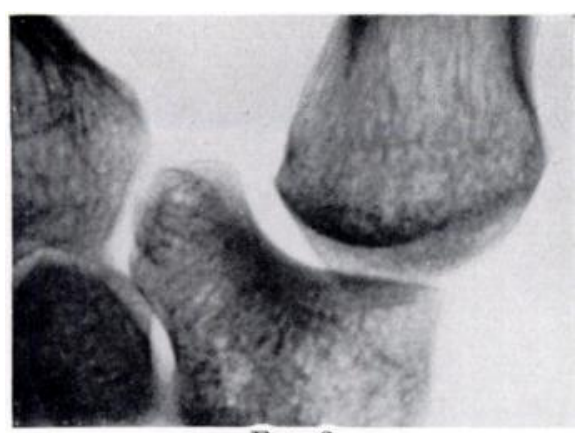

FIG. 3

Exaggeration of the normal concavity of the trapezium and prolongation of the medial and distal angle.

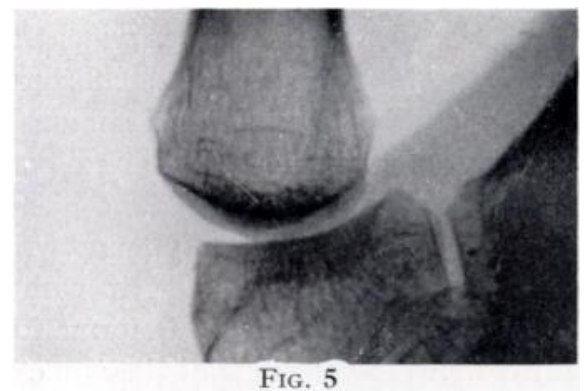

In adduction of the thumb the base of the metacarpal glides laterally.

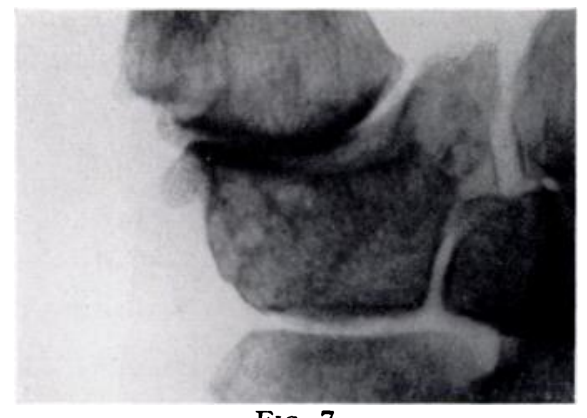

FIG. 7

Showing narrowing of the joint space, sclerosis of subchondral bone and osteophyte formation.

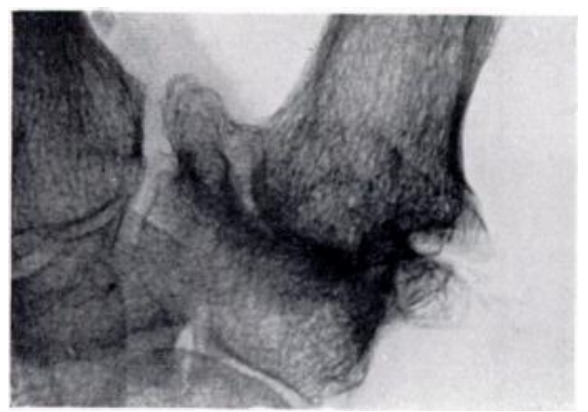

FIG. 9

To show osteophytes of unusual si\%e; at both the lateral and medial margins of the joint.

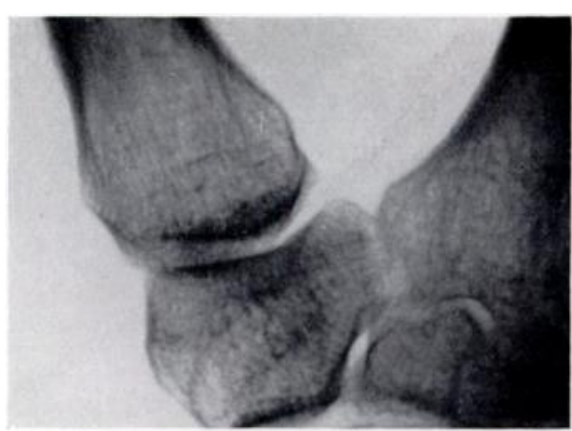

FIG. 4

In abduction of the thumb the base of the first metacarpal exactly fills the transverse hollow of the trapezium.

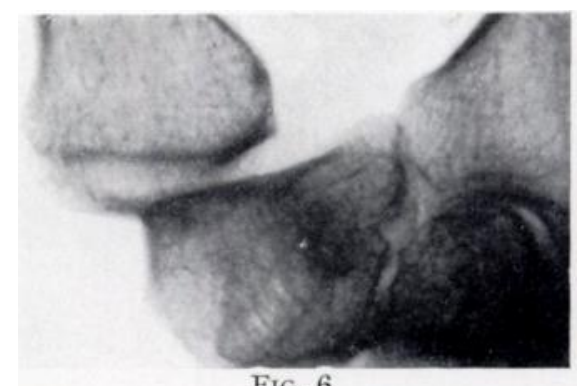

FIG. 6

Showing marked physiological subluxation of the metacarpal.

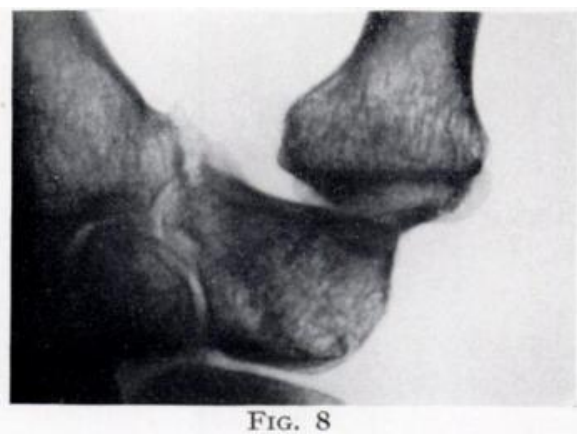

Osteophyte formation on the medial and distal angle of the trapezium, and lateral subluxation of the metacarpal.

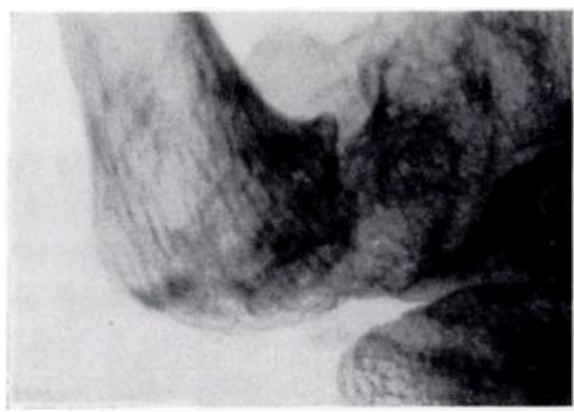

FIG. 10

La forme subluxante maxima: the base

of the metacarpal is level with the trapezio-scaphoid joint.

Vol. $31 \mathrm{~B}$, No. 4, November 1949 
oval image can often be seen with the long axis directed inwards and distally like the stone of a ring set obliquely (Fig. 2 ). The image ends in a rounded outline over the proximal ends of the first and second metacarpals. It is caused by the projection of the medial and distal part of the trapezium on to the rest of the bone. If an abnormality of the trapezio-metacarpal joint is suspected, a radiograph should be taken in a position of forced pronation, together with a view in profile. The position of the patient is important. To have the whole trapezium and all its borders properly displayed, the patient should kneel beside the table with the head bent forwards, the arm horizontal and the shoulder level with the hand (Fig. 1).

There are two groups of cases:

1) Early trapezio-metacarpal arthritis-Very often styptoms first arise during manual work. Radingraphic changes in the joint may include: a) Narrowing of joint space. A

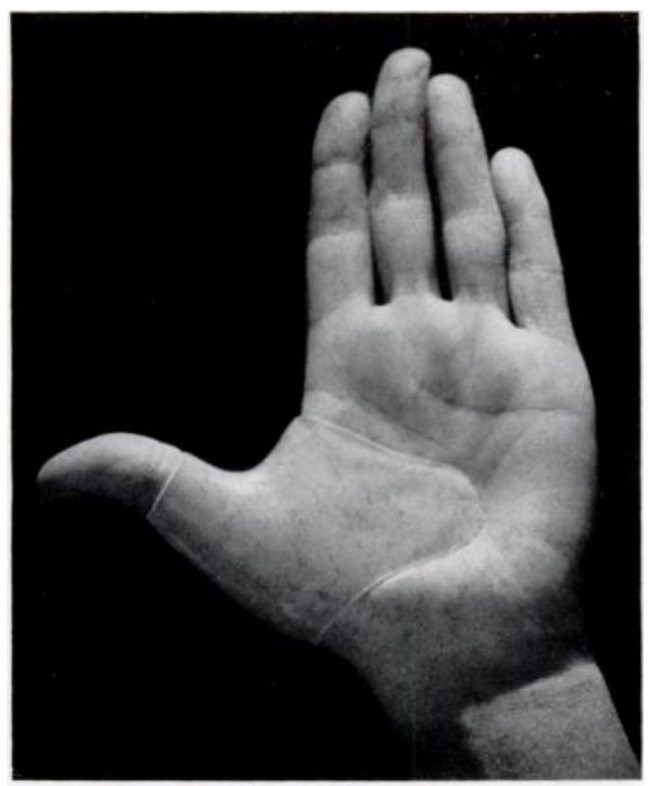

FIG. 11

A suitable appliance. reduction of $1 \cdot 0$ to $1 \cdot 5$ millimetres is common, but what is the margin of error? Stereoscopic examination always shows that the joint space is better outlined and much wider than it appears in routine radiographs. b) Subchondral condensation of bone. c) Lateral subluxation. d) Osteophyte formation on the lateral borders of the metacarpal and trapezium. Though this is given as an early sign by many writers, we have not been able to find it with any certainty in early cases. e) Deformation of the medial and distal angle of the trapezium. This is common and consists of an alteration in the distal curve of the trapezium beginning near the junction of the inner third and the outer two-thirds, prolongation of the distal and medial angle into the space between the proximal extremities of the first two metacarpals, and early osteophyte formation in the same region (Figs. 7 and 8). We think that the medial part of the articular surface is the starting point of the arthritic process and that this corresponds to the area where pressure transmitted through the adducted thumb is most frequently and powerfully felt.

2) Gross trapezio-metacarpal arthritis-The diagnosis can b: made clinically and the radiographs show clear details of the lesion (Fig. 9). In an extreme case dislocation can be so marked that the base of the metacarpal is opposite the traperio-scaphoid joint. This is the type with maximum subluxation, la forme subluxante maxima (Fig. 10). The joint space is not visible, but screening during movement shows that it is partly preserved. In all cases the greatest deformicy and largest osteophytes are at the distal and medial angle of the trapezium. This is a point of first importance.

Treatment-At the least suspicion of trouble the patient should wear an apparatus to hold the trapezio-metacarpal joint at rest in abduction (Fig. 11). We demonstrated a suitable appliance madie of a very light plastic material (Paladon) at the International Scientific Conference held at Aix-les-Bains in June 1948.

\section{REFERENCES}

Forestier, J. (1937): P'resse médicale, 45, 315.

Huc, (B., and Bante, .1. (1941): Revue du Rhumatisme, 8, 312.

I.ÉRI, A. (1926): Etudes sur les affections des os et des articulations. Paris: Nlasson et (ie.

Robert, P. (1936): Bulletins et mémoires de la Société de Radiologie médicale de France, 24, 687. 